\title{
Desarrollo de herramientas para favorecer el aprendizaje del inglés
}

\section{Developing tools to promote English learning}

\author{
CRUZ-LOERA, María de la Luz†, MONTECILLO-PUENTE, Francisco Javier y LÓPEZ-ENRIQUEZ, \\ Renato
}

Instituto Tecnológico Superior de Salvatierra. Calle Manuel Gómez Morín 300, Janicho, 38933 Salvatierra, Gto.

ID $1^{\mathrm{er}}$ Autor: María de la Luz, Cruz-Loera / ORC ID: 0000-0003-3756-948X, Resercher ID Thompson: X-2734-2019, CONACYT CVU ID: 1013405

ID $2^{\text {do }}$ Coautor: Francisco Javier, Montecillo-Puente / ORC ID: 0000-0001-9540-9228, Resercher ID Thompson: X2309-2018, CONACYT CVU ID: 50009

ID $3^{\text {er }}$ Coautor: Renato López-Enriquez / ORCID: 0000-0001-5708-3239, Resercher ID Thompson: Y-4493-2018, CONACYT CVU ID: 954847

\begin{abstract}
Resumen
El objetivo de este trabajo es la creación de herramientas para aprendizaje del idioma ingles utilizando realidad aumentada y robots humanoides, con la finalidad de interactuar con las personas de manera autónoma en el proceso de aprendizaje. Para esto se revisaron los contenidos de los programas y temarios de idioma ingles en nivel superior, se entrevistaron a jefes de área de idiomas y docentes, a fin de terminar temas cables en el aprendizaje del idioma. En la actualidad el contar con una segunda lengua en el ámbito de la educación hoy en día es considerada como una necesidad. Actualmente, las instituciones de nivel superior utilizan técnicas de aprendizaje del idioma inglés basada en libros, flashcards, diapositivas, audios, videos etc. De lo anterior se propone desarrollar herramientas de aprendizaje capases de interactuar con los usuarios de forma autónoma. Esto conlleva a resolver grandes problemas de aprendizaje haciendo uso de la interacción humano computadora y humano robótica. Lo que se presenta son dos herramientas para el aprendizaje del idioma inglés, la primera basada en realidad aumentada y la segunda usando robot humanoide Nao.
\end{abstract}

Autónomo, Aprendizaje, Herramientas

\begin{abstract}
The objective of this work is the creation of tools for learning the English language using augmented reality and humanoid robots, in order to interact with people autonomously in the learning process. For this, the contents of the English language programs and programs at the higher level were reviewed, language area heads and teachers were interviewed, in order to finish cable issues in language learning. At present, having a second language in the field of education today is considered a necessity. Currently, higher level institutions use English language learning techniques based on books, flashcards, slides, audios, videos, etc. From the above it is proposed to develop learning tools capable of interacting with users autonomously. This leads to solving major learning problems using human computer and robotic human interaction. What is presented are two tools for learning the English language, the first based on augmented reality and the second using Nao humanoid robot.
\end{abstract}

Autonomus, Learning, Tools

Citación: CRUZ-LOERA, María de la Luz, MONTECILLO-PUENTE, Francisco Javier y LÓPEZ-ENRIQUEZ, Renato. Desarrollo de herramientas para favorecer el aprendizaje del inglés. Revista de Didáctica Práctica. 2019. 3-8: 19-26.

$\dagger$ Investigador contribuyendo como primer autor. 


\section{Introducción}

La Realidad aumentada y los robots humanoides como el Nao han tenido un éxito importante en los últimos años, sus aplicaciones en la parte educativa y del entretenimiento es amplio. En un reporte de la Federación Internacional de Robótica IFR, World Robotics Report 2016, se menciona que se instalaron 36000 nuevos robots en USA, Canadá y México; además se indica que del 2010 al 2015 los principales desarrolladores de robot de USA, Europa y Asia instalaron 80000 robots. Esto nos da una idea de lo importante que los robots son en la actualidad para la industria y cuánto puede ser para la educación. Por otro lado, la realidad aumentada nos permite incorporar datos virtuales (imágenes, texto, audio, video, entre otos) a partir de un objeto del mundo real.

El área de oportunidad de la robótica y la realidad aumentada en la educación se refieren al uso de aplicaciones y de un robot humanoide para que apoyen el aprendizaje del alumno en entornos cotidianos.

La industria ha llevado la robótica al ámbito educativo por ejemplo con robots guía tipo humanoides como el robot Pepper de Softbank Robotics y robot NAO. Se adapta a cualquier nively está indicado en la participación del proceso de aprendizaje desde los 5 años hasta la universidad ya que admite desde niveles iniciales de programación hasta los más complejos desarrollos de investigación.

El NAO motiva el proceso de aprendizaje mediante sus múltiples sensores y su capacidad de comunicarse e interaccionar con los estudiantes. Para los profesores NAO se convierte en un elemento útil dentro del aula puesto que aumenta el interés en los estudiantes y dinamiza las clases. Gracias al completo y sencillo software que incluye, los alumnos de casi todos los niveles pueden programar al robot sin ningún riesgo pues cada alumno podrá probar sus experimentos y hacer las pruebas necesarias en un robot virtual.

Dentro de los retos que encuentra la robótica de servicio están la interacción hombremáquina que se acerca a la interacción humana: voz, gestos corporales y también la locomoción, planificación de movimientos y la evasión de obstáculos, y otras.
Por otro lado, el avance al desarrollo que se ha realizado para llevar la tecnología de Realidad Aumentada (RA) enriquece el proceso de enseñanza-aprendizaje y potencia habilidades clave para la formación académica y personal del alumnado.

Es una herramienta que motiva el motor del aprendizaje. "Lo que conseguimos con la RA es transformar el pensamiento abstracto en algo tangible, una imagen que puede ayudar mucho más que lo que explique o lea el profesor", apuntan Merín y Martínez. La RA se acerca a las emociones de los más pequeños hasta los jóvenes y adultos, esto hace tener un mejor alcance educativo para los alumnos.

En el caso de este artículo dedicado a los jóvenes de estudios superiores se logra por medio de un booklet de realidad aumentada el cual contiene imágenes con oraciones que se representa por medio de un dispositivo móvil Android. Por el otro lado también se presentan preposiciones con el movimiento de brazos del robot $y$ acciones que se indican mediante mensajes de voz esto facilita la adquisición del conocimiento.

El robot Nao tiene integrado un sistema de locomoción que puede desplazarse hacia delante, hacia atrás, lateral, frontal y hacia tras siguiendo trayectorias programadas lo cual facilita el empleo de aprendizaje de preposiciones de lugar; en este trabajo se plantea un sistema planificador de locomoción que incluye una nueva forma de movilización utilizando verbos o acciones y preposiciones más comunes para los alumnos de educación superior.

Con las características antes mencionadas presenta un planificador para NAO en simulación y para varios escenarios diferentes. Con este nuevo planificador de locomoción se ilustra en el movimiento de la palabra a los lados, (to the sides) 


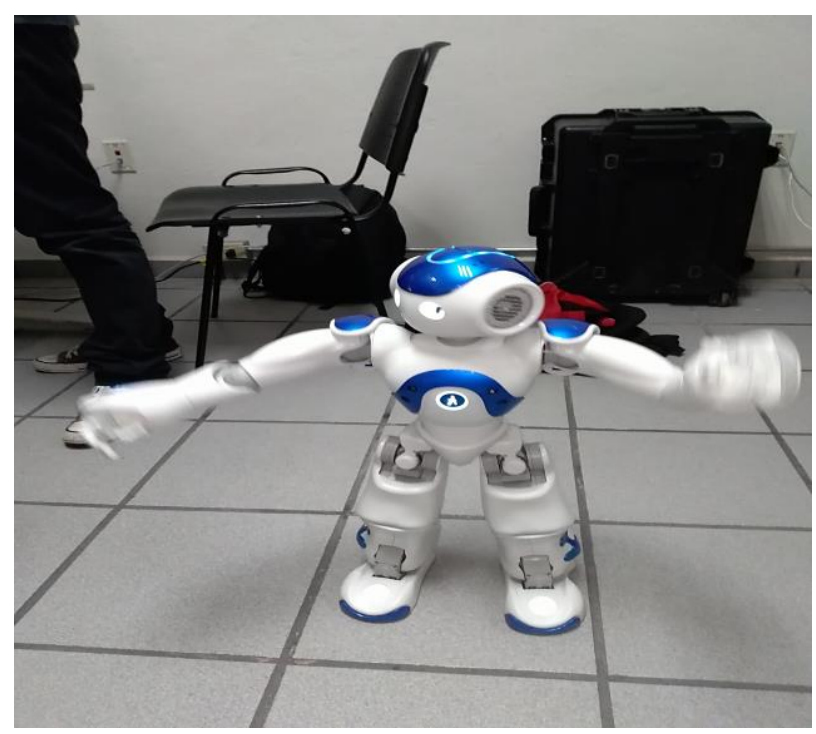

Figura 1 En esta imagen se muestra un caso donde el robot NAO desplazarse sus brazos a los lados para la instrucción de to the sides que significa a los lados

El contenido del artículo se presenta de la siguiente forma, en la siguiente sección 2 niveles de aprendizaje del idioma inglés, sección 3. Entrono de trabajo herramienta para realidad aumentada. Luego, en la sección 4 Entorno de trabajo Robot Humanoide. En la sección 5 Desarrollo de herramientas para el aprendizaje del idioma inglés mediante el robot NAO y Realidad Aumentadaluego en la sección 6 resultados, en la sección 7 y 8 las conclusiones $\mathrm{y}$ finalmente las referencias.

\section{Niveles de aprendizaje del idioma ingles}

Las universidades y los tecnológicos de México actualmente están interesados en que los estudiantes adquieran un nivel adecuado de inglés, afín de desarrollarse en un ámbito labora globalizado. Los niveles de ingles según el marco común europeo los cuales se definen a continuación:

i. Nivel A1 es un nivel que tiene la consigna de introducir al personal al inglés, sirve principalmente para que los alumnos tengan confianza y motivación a fin de que aprendan una segunda lengua, aporta un base mínimo necesario para el aprendizaje del idioma, este nivel busca certificar que una persona es capaz de transmitir conocimientos sencillos, realiza cuestionamientos y comunica lo esencial. En términos generales usa expresiones cotidianas y de uso frecuente, orientadas a satisfacer necesidades inmediatas. ii. Nivel A2. Busca que el estudiante sea capaz de comprender frases y expresiones que se relacionan con su área de experiencia, es decir información básica acerca de si mismo y de las personas que lo rodean. En este nivel se busca la destreza lectora y escrita, así como destrezas orales divididas en comprensión auditiva y capacidad de entablar una conversación.

iii. Nivel B1. En este nivel se busca que los estudiantes posean habilidades para comprender la lectura, escribir, comprensión auditiva e interacción oral, para poseer este nivel los estudiantes deben ser capaces de comprender los puntos mencionados anteriormente en un contexto de situaciones de trabajo, de estudio o recreativo. Deben ser capases de desenvolverse en entornos de habla del idioma y de escribir textos sencillos que involucren situaciones cotidianas $\mathrm{o}$ experiencias de acontecimientos o vivencias. Por último, debe ser capas de justificar dichas experiencias o vivencias.

iv. Nivel B2. El estudiante debe ser capaz de mantener conversaciones fluidas con personas nativas del idioma, esto sin presentar dificultades que interfieran en una conversación normal. Además, deberá ser capaz de elaborar textos a detalle, acerca de temas diversos, así como expresar distintos puntos de vista de temas generales. Si el estudiante se encuentra dentro de su campo de expertiz, este deberá ser capaz de entender textos complejos a un nivel técnico.

v. Nivel C2. Este nivel lo adquiere el estudiante una ves que sea capaz de comprender una gran diversidad de textos extensos, que involucran cierto nivel de complejidad, así como reconocer sentidos implícitos, es decir, cuando es evidente esfuerzos para buscar expresiones correctas que hagan efectivo y flexible el uso del idioma con fines académicos, profesionales o de recreación. En cuanto a la escritura este debe ser capaz de escribir textos detallados sobre temas complejos haciendo uso adecuado de mecanismos de organización, articulación y unión de textos. 
vi. Nivel C2. En este ultimo nivel el estudiante debe ser capaz de usar competencias lingüísticas necesaria en situaciones complejas con total eficacia y con perfección espontanea sin descubrir ningún problema. Su interacción debe tener un muy alto grado de fluidez y naturalidad.

Sin embargo, para que un estudiante pueda adquirir estos niveles, se requiere de personal altamente capacitado y del uso de herramientas que promuevan en el estudiante interés a fin de que adquieran cada uno de los niveles y logren ser eficientes y eficaces en el dominio de la lengua inglesas sin ningún tipo de obstáculos. Para esto se tiene que crear esenciaos y contextos que favorezcan un aprendizaje significativo. Además de incluir en estos escenarios tecnologías de la información y comunicaciones mediante realidad aumentada, sistemas de simulación y robótica.

\section{Entrono de trabajo herramienta para realidad aumentada}

Actualmente la realidad aumentada ha tenido una gran aceptación en la educación, debido a sus altas prestaciones. El uso de teléfonos inteligentes, no se limita al uso de aplicaciones tradicionales de comunicación y de socialización, sino que se vuelve una herramienta muy útil para el aprendizaje.

Dentro de las aplicaciones para aprendizaje esta el uso de realidad aumentada, la cual proporciona sensaciones de presencia. Para la elaboración de realidad aumentada existen actualmente aplicaciones de licenciamiento y de no licenciamiento, en este caso se optó por utilizar las siguientes herramientas.

i. Krita. Esta herramienta profesional gratuita y de código libre, permite pintar de forma digital, arte conceptual, texturas e ilustraciones.

ii. Api Vuforia. Es un plugin que se incrusta en el entorno de desarrollo, para su uso se requiere de una licencia libre, que se adquiere al registrarse en el sitio web del desarrollado. Se puede usar para fines educativos sin fines de lucro.

iii. Unity3d. Es un entorno que se puede utilizar al registrase en la pagina del creador, permite manipular entornos $3 \mathrm{~d}$. e puede usar sin fi fines de lucro.
Para la realización de una aplicación de realidad aumentada se deben contemplar los siguientes complementos: uso de imágenes, texturas, tipografías, sonidos, animaciones, uso de ventanas, efectos de iluminación, modelos 2D, interacción mediante cámaras y pantalla táctil.

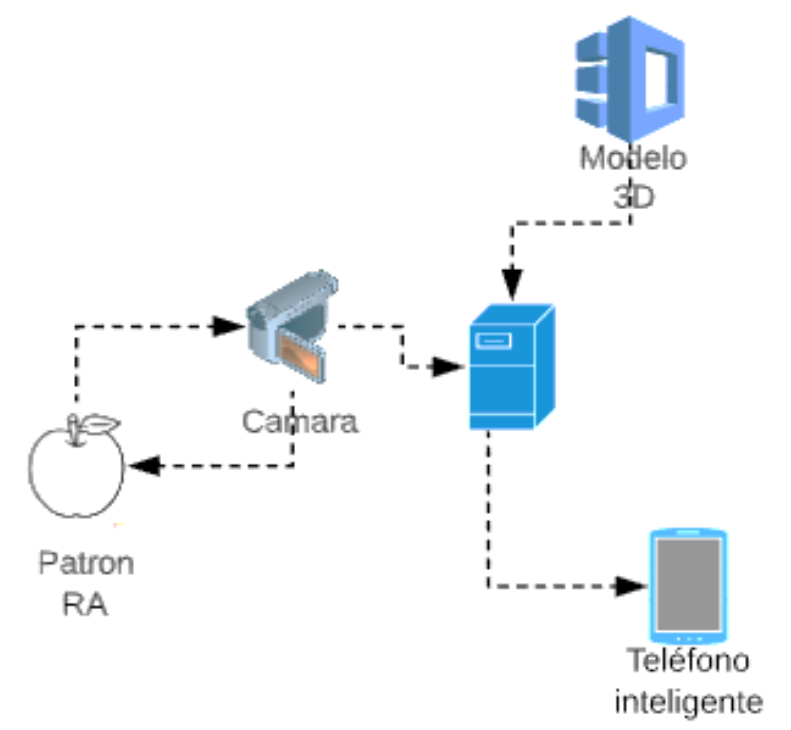

Figura 2 Modelo para procesamiento de patrones mediante realidad aumentada.

En cuanto al desarrollo de aplicaciones de realidad aumentada se involucra un equipo de trabajo de profesionales, tales como programadores, diseñadores, animadores por listar algunos. En cuanto al proceso de desarrollo de la herramienta se considera la fundamentación o estado de arte, análisis, diseño, codificación, pruebas y documentación.

\section{Entorno de trabajo Robot Humanoide.}

El uso de robots en la educación para el aprendizaje de una segunda lengua actualmente se encuentra en una etapa inicial, esto debido a las dificultades para contar con un equipo de este tipo, debido a su costo, sin embargo, en la actualidad existen simuladores de robos, los cuales integran herramientas de audio y texto, que permiten desarrollar aplicaciones orientadas al uso de robots humanoides. Para desarrollar la herramienta de aprendizaje del idioma ingles se consideraron:

Hardware: Robot Nao Version 4, Router Cisco Aironet AIR-AP1142N-N-K9, Workstation Pro Desk

Software: Sistema operativo GNU Linux Ubuntu 18.04 LTS, Choreographe v2.1.4

CRUZ-LOERA, María de la Luz, MONTECILLO-PUENTE, Francisco Javier y LÓPEZ-ENRIQUEZ, Renato. Desarrollo de herramientas para favorecer el aprendizaje del inglés. Revista de Didáctica Práctica. 2019 
Además de la integración de distintos entornos de desarrollo y un robot humanoide NAO. A continuación, se especifican las herramientas usadas:

i. Suite Choregraphe con sus librerías para la versión 4 del robot NAO.

ii. Router cisco Aironet 2800.

iii. Python SDK, C++ SDK y Bonjour SDK.

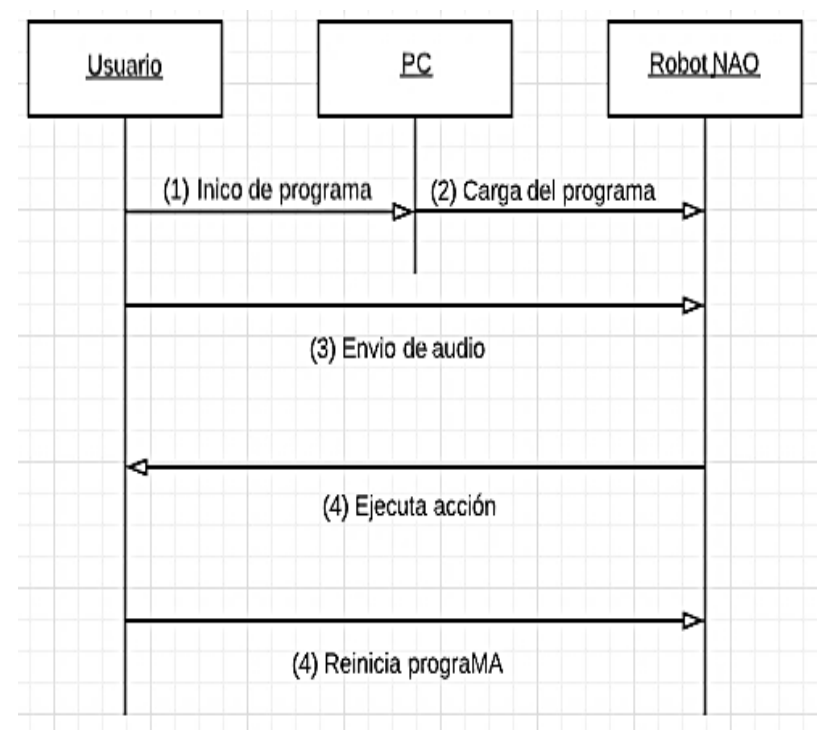

Figura 3 Diagrama de secuencias procesamiento de audio y ejecución de acciones mecánicas

En cuanto al desarrollo de la herramienta, se requieren programadores, diseñadores, traductores por mencionar algunos.

\section{Desarrollo de herramientas para el aprendizaje del idioma inglés mediante el robot NAO}

Para presentar el estudio sobre las herramientas para fortalecer el aprendizaje se realizaron 25 pruebas para la herramienta de realidad aumentada y 20 encuestas para el Nao. Coincide que el $90 \%$ de los alumnos denotan el gran interés, empatía y rápida adquisición del de conocimientos. Para llegar a ese resultado se planificaron los movimientos en base los verbos y preposiciones más comunes. El problema de planificación de movimientos consiste en dados un conjunto de acciones, determinar una ruta para plantear una la planificación de movimientos y resolverlo de las siguientes partes: a) Configuración de la estación de trabajo y del Robot Nao para el desarrollo del proyecto: instalar programa QiChat, Choreographe.

b) Crear un comportamiento. De la biblioteca disponible se pueden seleccionar diferentes acciones que se interrelacionan a través de diagramas de flujo $y$ se traducen en comportamiento de NAO, tanto desde la plataforma virtual como desde el robot NAO.

c) Selecciona las cajas de la librería con acciones disponibles.

d) Arrastra y suelta las cajas en el panel de diagrama de flujo.

e) Conéctalas entre sí para definir cómo se va a llevar a cabo la secuencia ya sea para las acciones o para las preposiciones.

f) Reunir la documentación, imágenes y animaciones necesarias para la realizar el material educativo en inglés y programarlas en el robot Nao.

g) Determinación y programación de los movimientos necesarios para cada palabra $\mathrm{u}$ oración el lenguaje con el lenguaje de propósito general.

h) Implementación de las técnicas y estrategias que se llevaron a cabo en el robot Nao, revisando concordancia entre palabras y movimientos.

i) Prueba del modelo de estrategia de aprendizaje de un nuevo lenguaje con los alumnos.

j) Realizar el análisis entre el aprendizaje tradicional y mediante el apoyo del robot Nao. 


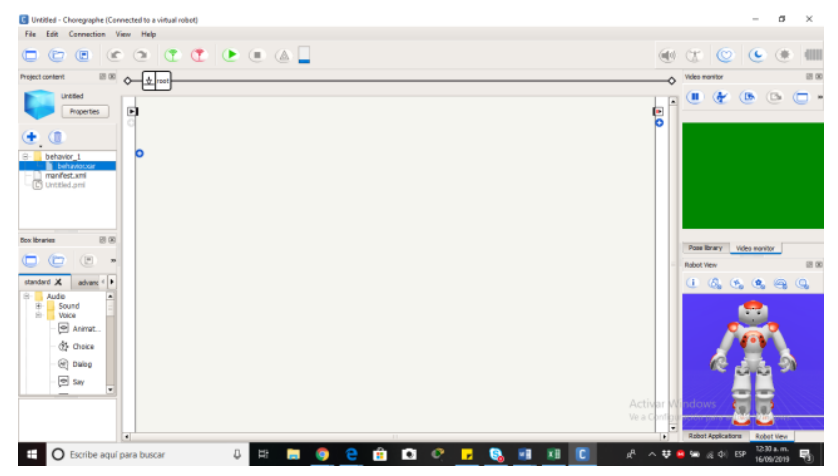

Figura 4 El robot es controlado a través del software Choregraphe, que es el espacio donde puedes programar el robot. El software se puede programar en lenguaje Python

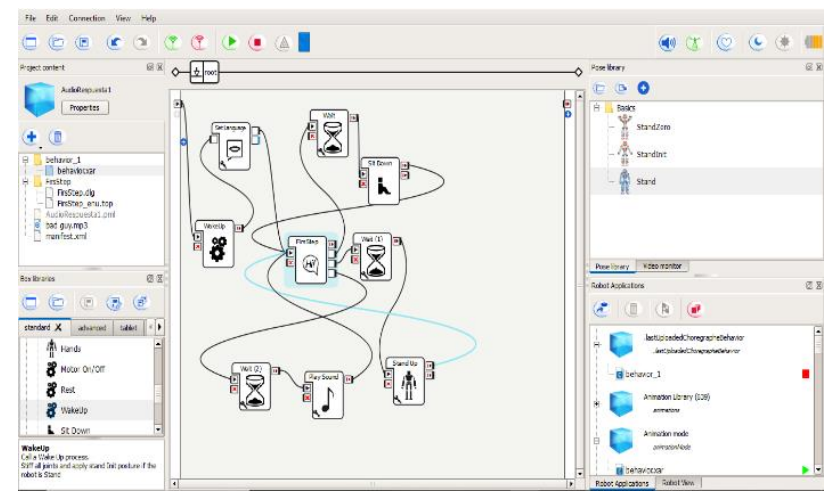

Figura 5 El modelado se hace por medio de bloques unidos a para programar movimientos y voz

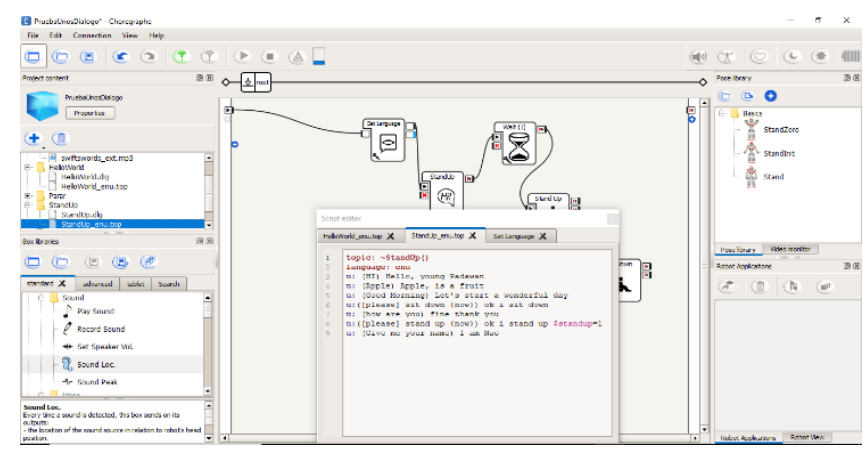

Figura 6 Se muestra como se captura el dialogo para la interacción por medio de la voz

\section{Desarrollo de herramienta con realidad aumentada (RA)}

Para presentar esta herramienta se tomó en cuenta las encuestas y pruebas realizadas a un grupo de los alumnos de primer semestres de inglés. Y se obtuvo el $93 \%$ de aceptación, pues se les facilito la adquisición del aprendizaje. En esta herramienta de realidad Aumentada realizamos los siguientes:

a) Configuración la estación de trabajo para el desarrollo del proyecto: instalar programa de propósito general, Unity, Krita, plugins de Vuforia y Android studio. b) Reunir la una base de datos los verbos o acciones más comunes de inglés para desarrollar las imágenes y animaciones necesarias para la realizar el material educativo en inglés. Para ello se utilizó el software Krita con una tableta Wacon para el diseño

c) Se determina los parámetros de animación para cada uno de los sprints. Se toma en cuenta que tan atractivos y adecuados las animaciones para la creación del modelo final de Realidad Aumentada

d) Se realizan pruebas del software para diferentes modelos de móviles Android. consultan las fuentes para realizar las pruebas pertinentes a un grupo de alumnos. los alumnos de la institución en su primer nivel de inglés.

e) Se realiza un booklet donde se integran oraciones con las imágenes RA y inician con las pruebas del modelo Realidad Aumentada con los alumnos.

f) Realizar el análisis entre el aprendizaje tradicional y mediante realidad aumentada. Una vez obteniendo el resultado de las pruebas.

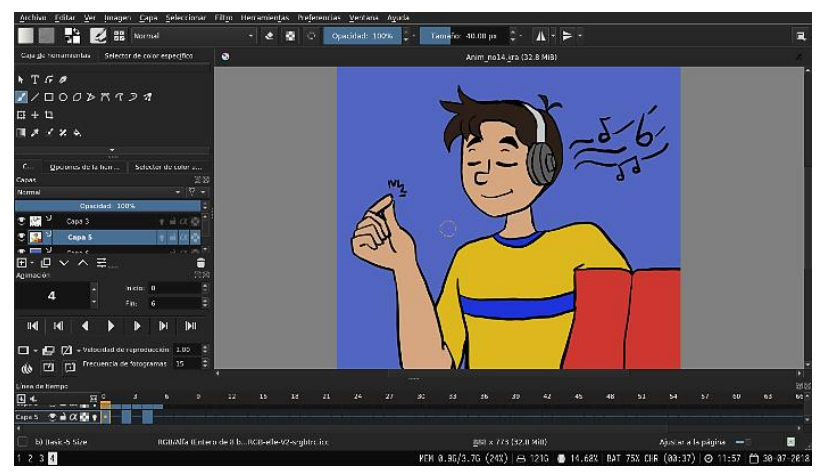

Figura 7 Se muestra uns sprite diseñado utilizando el sortware Krita. Indica la acción de listen. En movimiento se encuentra en los dedo y en las letras de música que se ubicada en la parte superior izquierda. 


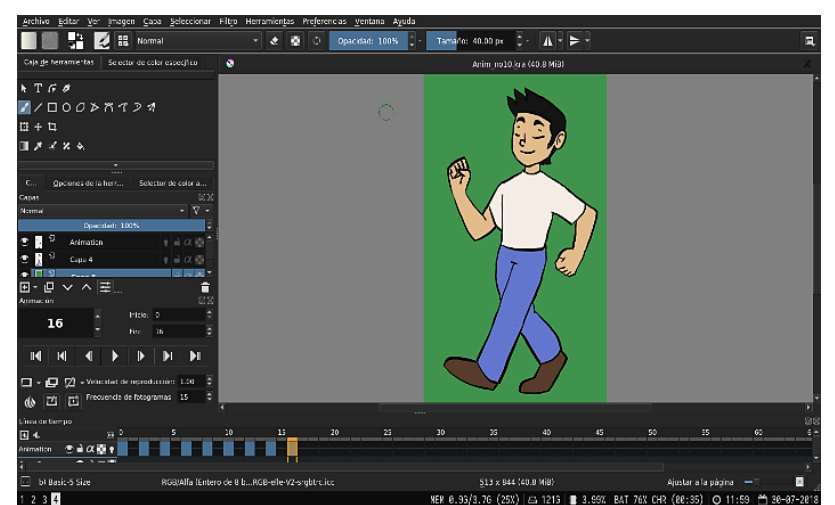

Figura 8 Se muestra otro sprites La acción que se representa indica la acción de walk. En movimiento se realiza haciendo la simulación del movimiento de manos y piernas.

\section{Resultados}

Las librerías, el software requerido para llevar acabo la herramienta con el NAO fueron instaladas satisfactoriamente.Se realizaron las pruebas pertinentes para evaluar el grado de aprendizaje comparando el modelo tradicional y el modelo asistido por Nao. En el resultado se aprecia el modelo asistido por el Nao tiene grandes ventajas, dado que hay un interacción con la herramienta y es fuera de lo común, es más atractivo para los jóvenes y por tanto se involucran más intentado lograr la meta que es el reconocimiento de la palabra por el robot (preposición), lo cual permite que por medio de la repetición se fomente y refuerce su acento en el lenguaje, esto por medio de la práctica.

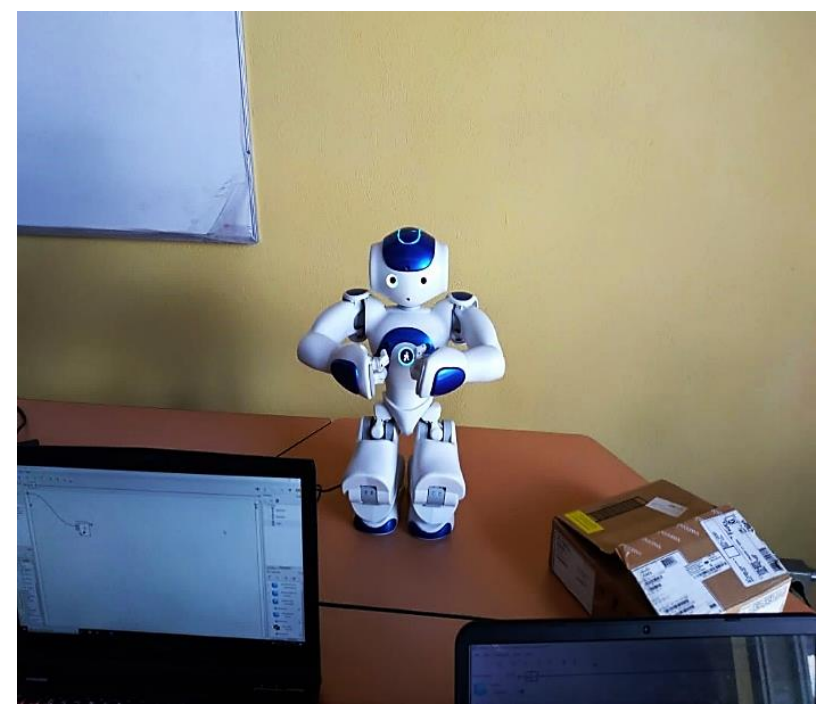

Figura 9 Se muestra la imagen del robot Nao donde muestra una simulación de la preposición Between (entre)

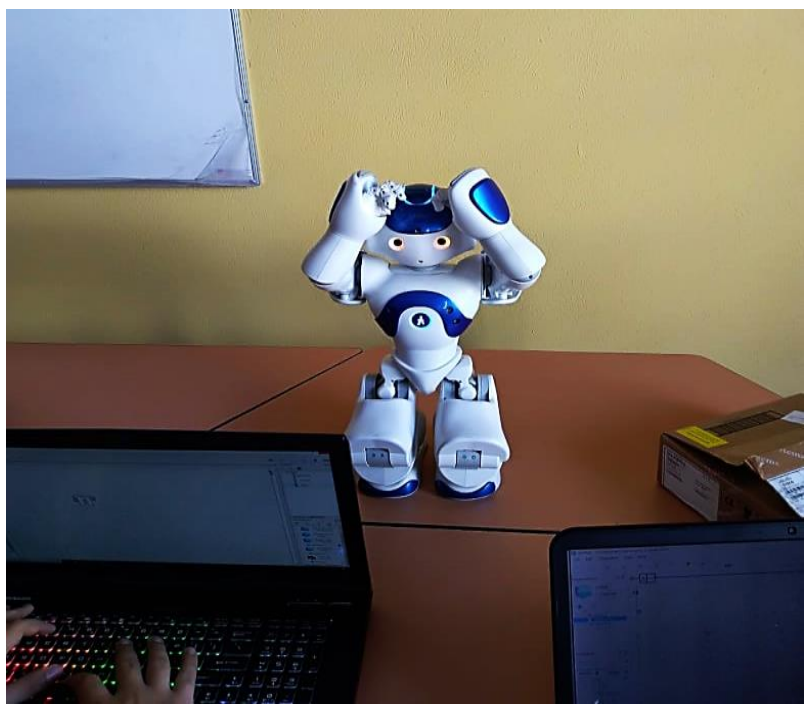

Figura $10 \mathrm{La}$ muestra la imagen del robot Nao donde muestra una simulación de la preposición Between (entre)

Con la herramienta de realidad aumentada se observó un aprendizaje muy favorable, pues los alumnos adquirieron más atención y retención en el aprendizaje utilizando la aplicación desde su teléfono móvil. Se mostró un incremento de aceptación muy significativo en las encuestas y quedaron satisfechos con el resultado obtenido en sus exámenes. Por ello se pidió implementar esta herramienta como complemento a los cursos de inglés que se imparten en la institución.

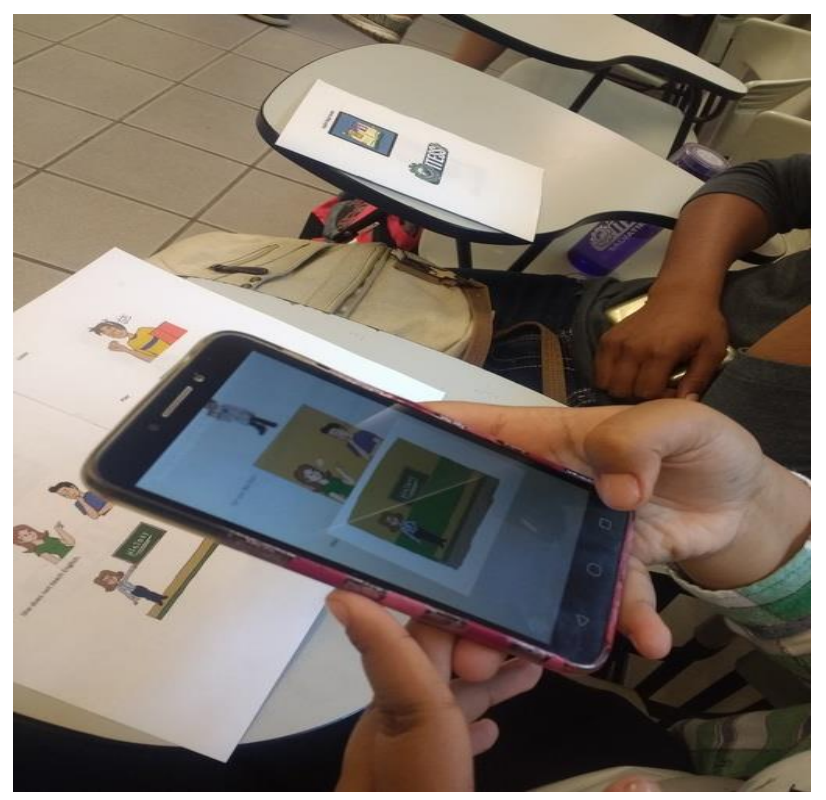

Figura 11 Se muestra la imagen de la RA aplicada en móviles android en la prueba que se aplicó a los alumnos. De la imagen del booklet a la imagen del móvil donde se realizaba la acción 


\section{Conclusiones}

Las herramientas para asistir el aprendizaje sin duda son eficiente comparado con el sistema tradicional. Se toma en cuenta que estas herramientas son innovadoras en la parte de la enseñanza- aprendizaje, son interactivas, atractivas y debido a que las tecnologías van cambiando día a día los robots se van volviendo más populares al igual que la RA. Debido a ello se tiene más atención en las lecciones, esto seguido de las ganas de participar e interactuar. Un atractivo más a estas herramientas en el caso del Nao es el reconocimiento de voz, pues ayuda a evaluar el nivel de pronunciación de los alumnos, lo cual lleva a seguir practicando por medio de la repetición. Sin embargo tiene su desventaja pues el costo de adquisición es muy elevado y reduce por tanto las probabilidades de que se tenga en las escuelas de bajo poder adquisitivo.

Por otro lado la herramienta de RA está más al alcance del bolsillo de todos pues se cuenta con dispositivos móviles y también se observó una gran aceptación. Solo hay que pulir e incrementar diferentes habilidades dentro de la aplicación tales como pronunciación, ejercicios de relación y muy probable también reconocimiento de voz.

\section{Referencias}

Cristina Juárez Landín (2016) Nao como estrategia pedagógica para formar competencias en los estudiantes de licenciatura. Centro Universitario Valle de Chalco/Universidad Autónoma del Estado de México

\section{Nikolay Zeveke,(2014),NAO Robot Course translation Nikola Zeveke}

Documentacion del Nao 2018. Obtenido de http://doc.aldebaran.com/2-1/home_nao.html.

Merin y Martinez, (2018) Realidad Aumentada para potenciar la capacidad de innovacion del alumnado. Educacion 3.0 medio de comunicación líder en innovación educativa,nuevas tecnologías y metodologías,innovación docente, formación y recursos para profesores.

Noelia M. Moreno, Realidad Aumentada y Educación,Octaedro,2016
Julio C. Cabero, Realidad Aumentada: Tecnologia para la formacion, Sintesis, 2016

Jung Udo O.H. The Use of Multimedia in Teaching. Allwright Dick; Else V. Hamayan; Udo O.H. Jung; et al. Encyclopedia of Language and Education. Springer. Dordretch 1997.

Fitzgerald Elizabeth; Rebecca Ferguson; Anne Adams; et al. Augmented Reality and Mobile Learning: The State of the Art. International Journal of Mobile and Blended Learning. https://www.igi-global.com/article/augmentedreality-and-mobile-learning/99679

Goodwin-Jones Robert. Augmented Reality and Language Learning: From Annoted Vocabulary to Place-based Mobile Games. Virginia 2016.

Kajita, S., Kanehiro, F., Kaneko K., Fujiwara, K., Harada, K., Yokoi, K. \& Hirukawa, H. (2003). Biped walking pattern generation by using preview control of zero-moment point. IEEE International Conference on Robotics and Automation, 2003. Proceedings ICRA'03.

The Better Learning Through Augmented Reality: AR and the Classroom. https://www.pdx.edu/honors/sites/www.pdx.ed u.honors/files/AR_and_the_classroom.pd

World Robotics Report 2016. (2016). Obtenido de http://www.ifr.org/: http://www.ifr.org/news/ifr-pressrelease/world-robotics-report-2016-832/ 